\title{
COMUNICAÇÃO
}

\section{SCHISTOSOMAL GLOMERULONEPHRITIS: IS IT MORE PREVALENT IN HEPATOSPLENIC PATIENTS WHEN COR PULMONALE IS PRESENT?}

\author{
W. L. C. Santos1, E. A. G. Ramos1, L. J. Pereira2, R. Martinelli2, \\ E. Brito 2 , Z. A. Andrade1 and H. Rocha2.
}

S. mansoni infection can produce damage in several organs, in some due to immunological alterations such as the development of glomerulopathy ${ }^{2}$ and in others, at least in great part, due to vascular obstruction related to egg deposition, such as chronic cor pulmonalel. Both situations are essentially observed in patients with the hepatosplenic form of the parasitic infection.

There are reports in the literature suggesting that a chronic increase in renal vein pressure may favour the development of glomerulopathy and/or nephrotic syndrome, such as has been described in chronic congestive pericarditis, renal vein thrombosis or chronic congestive heart failure 345 .

Even though the increase in renal vein pressure may not be a cause of glomerulopathy, there is some agreement that it could exacerbate a previously existent proteinuria ${ }^{3}$. In chronic cor pulmonale due to $S$. mansoni infection, besides the immunological alterations related to the parasitic infection, there is frequently heart failure, with severe systemic conges- tion. It would be logical to assume, then, that patients with hepatosplenic schistosomiasis and cor pulmonale should have more frequent (or, perhaps more intense) glomerulopathy or proteinuria than similar patients without cor pulmonale. To investigate this question, a total of 20 (twenty) patients with hepatosplenic schistosomiasis and cor pulmonale (Group I) were compared with 20 others with schistosomal hepatosplenomegaly without cor pulmonale (Grupo II), matched according to ager and sex. All cases had been autopsied at the University Hospital of Federal University of Bahia. Schistosomal cor pulmonale was defined as hypertrophy of the right ventricle ( $\geq 0.5 \mathrm{~cm}$ thickness), with a normal left ventricle, pulmonary arteritis with multiple granulomas around eggs of the parasite, and systemic venous congestion. In each group, 10 (ten) patients were male and 10 (ten) female with an average of $15.3 \pm 14.2$ years for Group I and $26.5 \pm 14.3$ for Group II. There was no significant difference in the occurrence of arterial hypertension, microscopic hematuria nor the nephrotic syndrome (Table 1).

Table 1 - Some clinical data in patients with hepatosplenic schistosomiasis with (Group I) and without (Group II ) cor pulmonale.

\begin{tabular}{lcc}
\hline Clinical Characteristics & Group I (20 Pts) & Grou II (20 Pts) \\
\hline Age (years) & $25.3 \pm 14.2$ & $26.5 \pm 14.3$ \\
Sex & $10 \mathrm{M} ; 10 \mathrm{~F}$ & $10 \mathrm{M} ; 10 \mathrm{~F}$ \\
Arterial Hypertension & $11.1 \%$ & $6.5 \%$ \\
Microscopic Hematuria & $10.0 \%$ & $23.5 \%$ \\
Nephrotic Syndrome & $20.0 \%$ & $11.8 \%$ \\
Glomerulonephritis * & $23.5 \%$ & $35.7 \%$ \\
\hline
\end{tabular}

* Mesangial proliferative, focal glomerulosclerosis, mesangio-capillary glomerulonephritis or membranous glomerulonephritis.

1. Centro de Pesquisas Gonçalo Moniz/FIOCRUZ, R. Valdemar Falcão, 121 - Brotas, Salvador-BA.

2. Serviço de Nefrologia do Hospital Prof. Edgard Santos, Universidade Federal da Bahia, Campus Universitário do Canela - Salvador-BA.

Endereço para correspondència: Dr. Washington Luis Conrado dos Santos - Centro de Pesquisas Gonçalo Moniz/ FIOCRUZ - R. Valdemar Falcāo, 121 - Brotas, SalvadorBA.

Recebido para publicação em 10/2/89.
In all cases, histological study of kidneys was carefully done by two pathologists, without knowledge of the group from which the patient originated. The existence and detailed characteristics of glomerulopathy was reported. If a discrepancy occurred, the pathologists reviewed the case together and tried to come to agreements. The occurrence of significant glomerular lesions was reported in 23.5 of Group $I$ and $35.7 \%$ in Group II (no statistical difference $(p=0.23$ ) - exact Fisher's test). The types of lesions described 

rulonephritis: Is it more prevalent in hepatosplenic patients when cor pulmonale is present? Revista da Sociedade Brasileira de Medicina Tropical 22: 51-52, jan-mar, 1989.

were: mesangial proliferative glomerulonephritis, focal glomerulosclerosis and a single case of membronous nephropathy. It seems, then, that the existence of a chronic increase in renal vein pressure such as is observed in chronic schistosomal cor pulmonale, does not affect the occurrence or severity of glomerulonephritis.

\section{REFERENCES}

1. Andrade ZA, Andrade SG. Pathogenesis of schistosomal pulmonary arteritis. American Journal of Tropical Medicine and Hygiene 10: 305-310, 1970.
2. Andrade ZA, Rocha H. Schistosomal glomerulopathy. Kidney International 16:23-29, 1979.

3. Glassock RJ, Cohen AH, Bannett CM, Martinez-Maldonado M. Primary glomerular disease. In: Brenner BM, Rector FC (eds). The kidney, 2nd edition, W.B. Saunders Co., Philadelphia, p. 1351-1492, 1981.

4. Pastor BH, Cahn M. Reversible nephrotic syndrome resulting from constrictive pericarditis. The New England Journal of Medicine 262:872-874, 1960.

5. Thayer BJM, Gleckler WJ, Holmes RO. The development of the nephrotic syndrome during the course of congestive heart failure: case report and review of the literature. Annals of Internal Medicine 54:1013-1025, 1961. 